DOI: $10.15593 / 2224-9982 / 2021.64 .09$

УДК $629,621.4$

\author{
А.А. Шилова, Н.Л. Бачев, Р.В. Бульбович
}

Пермский национальный исследовательский политехнический университет, Пермь, Россия

\author{
ВЛИЯНИЕ ПОДОГРЕВА ГАЗОВОЗДУШНОЙ СМЕСИ \\ НА ХАРАКТЕРИСТИКИ ГОРЕНИЯ ТОПЛИВНЫХ ГАЗОВ
}

\begin{abstract}
Для стабильного положения фронта пламени в камерах сгорания газотурбинных энергоустановок свежая газовоздушная смесь в течение всего процесса работы должна быть нагрета до температуры воспламенения. При коэфффициентах избытка воздуха в интервале между верхним и нижним концентрационными пределами с этой задачей успешно справляются обратные токи из зоны развитого горения. При организации низкотемпературного горения вблизи бедного предела вклад обратных токов в подогрев свежей газовоздушной смеси оказывается недостаточным и дополнительно требуется внешний подогрев компонентов в специальных подогревателях отработанными на турбине газами. Температурные характеристики свежей газовоздушной смеси на входе в камеру и в зоне обратных токов, а также продуктов сгорания в зоне развитого пламени, получены из решения уравнений энергетического баланса. Рассмотрены режимы низкотемпературного бедного горения с коэфффициентами избытка воздуха, превышающими нижний концентрационный предел $\alpha_{\mathrm{H}}=2$. Расчеты проведены при двух значениях коэффициента эжекции в зоне обратных токов $K=0,14$ и $K=0,30$. Значение $K=0,14$ получено с использованием эмпирических соотношений. Значение $K=0,30$ получено из условия, что при стехиометрическом горении подогрев газовоздушной смеси полностью осуществляется обратными токами. Показано, что с увеличением коэффицциента избытка воздуха для обеспечения устойчивого положения фронта пламени роль внешнего подогрева компонентов возрастает.

Ключевые слова: газовоздушная смесь, параметры подачи, устойчивость горения, коэффрициент избытка воздуха, коэффрициент эжекции, стабильное пламя, низкотемпературное бедное горение, зона обратных токов, внешний подогрев.
\end{abstract}

\author{
A.A. Shilova, N.L. Bachev, R.V. Bulbovich
}

Perm National Research Polytechnic University, Perm, Russian Federation

\title{
INFLUENCE OF HEATING OF A GAS-AIR MIXTURE ON THE CHARACTERISTICS OF COMBUSTION OF FUEL GASES
}

For a stable position of the flame front in the combustion chambers of gas turbine power plants, the fresh gas-air mixture must be heated to the ignition temperature during the entire operation process. With air excess coefficients in the interval between the upper and lower concentration limits, reverse currents from the zone of developed combustion successfully cope with this task. When organizing low-temperature combustion near the lean limit, the contribution of reverse currents to heating the fresh gas-air mixture turns out to be insufficient and additional external heating of the components in special heaters with exhaust gases from the turbine is required. The temperature characteristics of the fresh gas-air mixture at the inlet to the chamber and in the zone of return currents, as well as combustion products in the developed flame zone, were obtained from the solution of the energy balance equations. The modes of low-temperature lean combustion with excess air coefficients exceeding the lower concentration limit $\alpha=2$ are considered. The calculations were carried out for two values of the ejection coefficient in the zone of reverse currents $\mathrm{K}=0.14$ and $\mathrm{K}=0.30$. A $\mathrm{K}$ value of 0.14 was obtained using empirical relationships. The value $\mathrm{K}=0.30$ was obtained from the condition that during stoichiometric combustion, the gas-air mixture is heated completely by reverse currents. It is shown that with an increase in the excess air ratio to ensure a stable position of the flame front, the role of external heating of components increases.

Keywords: gas-air mixture, supply parameters, combustion stability, coefficient of excess air, ejection coefficient, stable flame, low-temperature lean combustion, reverse flow zone, external heating.

В работах [1-7] показано, что подача воздуха и топливного газа в подогретом состоянии в камеру сгорания (КС) газотурбинной установки (ГТУ) расширяет пределы концентрационных пределов горения и повышает эффективность работы ГТУ. Дополнительный подогрев компонентов может быть осуществлен в специальных теплообменниках-подогревателях отработанными на турбине газами [8-10].

C точки зрения расширения предела бедного горения особенно актуальным является подогрев топливного газа перед его подачей в КС [11-14]. 
Затраченная тепловая мощность газотурбинной энергоустановки может быть представлена следующим образом:

$$
Q_{3}=m_{\text {газ }} h_{\text {газ. вых }}-m_{\text {ок }} h_{\text {ок. вх }}-m_{\text {гор }} h_{\text {гор. вх }} \text {. }
$$

Увеличение энтальпий окислителя $h_{\text {ок.вх }}$ и топливного газа $h_{\text {гор.в }}$ на входе в КС приводит к снижению тепловых затрат $Q_{3}$. В классических ГТУ при использовании углеводородных топлив с высокой теплотой сгорания расход топливного газа составляет обычно 1-2\% от расхода воздуха, поэтому с точки зрения эффективности ГТУ целесообразным является дополнительный подогрев воздуха перед его подачей в КС [8-10].

Организация низкотемпературного бедного горения на нижнем пределе при внешнем подогреве топливного газа предполагает увеличение среднерасходной скорости газовоздушной смеси (ГВС) перед фронтом горения. С одной стороны, устойчивое положение фронта пламени наблюдается при определенном соотношении между среднерасходной скоростью и скоростью турбулентного горения ГВС $[15,16]$. С другой стороны, для поддержания стабильного горения температура ГВС перед фронтом пламени в любой момент времени должна достигать температуры воспламенения.

Для нагрева и воспламенения свежей ГВС требуется значительное количество тепла. На режиме запуска КС теплоподвод к свежей ГВС осуществляется от специального зажигательного устройства, а на установившемся режиме - из зоны развитого горения и внешнего теплоподвода.

Предварительные расчеты показывают, что лучеиспусканием и теплопроводностью из зоны развитого горения подводится не более $40 \%$ тепла, необходимого для нагрева и воспламенения свежей ГВС, а основное тепло поступает за счет конвективной теплоотдачи от обратных токов горячих газов. Обратные токи возникают в результате эжектирующего эффекта при обмене количеством движения между подводимой ГВС и продуктами сгорания.

В данной работе рассматривается комбинированный способ нагрева ГВС с помощью обратных токов из зоны развитого горения и внешнего подогрева ГВС до подачи в КС.

Уравнение теплового баланса в зоне обратных токов (3ОТ):

$$
Q_{\text {газ }}+Q_{\text {ГвС }}=Q_{\text {зот }} \text {. }
$$

Тепловая мощность, вносимая в ЗОТ обратными токами от зоны развитого горения,

$$
Q_{\text {газ }}=\dot{m}_{\text {газ }} c_{\text {р газ }} T_{\text {газ }},
$$

где $\dot{m}_{\text {газ }}-$ секундный массовый расход обратных токов; $c_{\text {ргаз }}, T_{\text {газ }}-$ удельная изобарная теплоемкость и температура продуктов сгорания.

Тепловая мощность, вносимая горючевоздушной смесью в ЗОТ,

$$
Q_{\text {ГВС }}=\dot{m}_{\text {ГВС }} c_{\mathrm{p} \mathrm{ГВС}} T_{\text {ГВС }},
$$

где $\dot{m}_{\text {гвС }}-$ секундный массовый расход ГВС; $c_{\mathrm{p} \mathrm{гвС}}, T_{\text {гвс }}-$ удельная изобарная теплоемкость и температура ГВС.

Тепловая мощность образованной смеси в 3OT

$$
Q_{\text {зот }}=\left(\dot{m}_{\text {газ }}+\dot{m}_{\text {ГВС }}\right) c_{\text {р зот }} T_{\text {зот }},
$$

где $c_{\text {рзот }}, T_{\text {зот }}$ - удельная изобарная теплоемкость и температура перемешанной смеси в 3ОT.

Тогда уравнение теплового баланса для ЗОТ выглядит следующим образом:

$$
\begin{gathered}
\dot{m}_{\text {газ }} c_{\mathrm{p} \mathrm{газ}} T_{\text {газ }}+\dot{m}_{\text {ГВС }} c_{\mathrm{p} \text { гВС }} T_{\text {ГВС }}= \\
=\left(\dot{m}_{\text {газ }}+\dot{m}_{\text {ГВС }}\right) c_{\mathrm{p} \text { зоТ }} T_{\text {зОТ }} .
\end{gathered}
$$

Определим коэффициент эжекции в зоне обратных токов как отношение расхода эжектированного из пламени газа $\dot{m}_{\text {газ }}$ к расходу эжектирующей струи ГВС $\dot{m}_{\text {ГВС }}$ :

$$
K=\frac{\dot{m}_{\mathrm{ra3}}}{\dot{m}_{\mathrm{\Gamma BC}}} .
$$

Тогда уравнение теплового баланса выглядит следующим образом:

$$
K c_{\text {р газ }} T_{\text {газ }}+c_{\text {р гвС }} T_{\text {ГВС }}=(K+1) c_{\text {р зот }} T_{\text {зОт }} .
$$


Удельная теплоемкость в 3ОТ

$$
c_{\text {р зот }}=K c_{\text {р газ }}+(K-1) c_{\text {р гвС }} \text {. }
$$

Следовательно, температура в 3ОТ

$$
T_{\text {зот }}=a T_{\text {ГВС }}+b T_{\text {газ }} \text {, }
$$

где коэффициенты $a$ и $b$ равны;

$$
a=\frac{1}{(K+1)} \frac{c_{\mathrm{p} \text { гвС }}}{c_{\mathrm{p} \text { Зот }}} ; b=\frac{K}{(K+1)} \frac{c_{\mathrm{p} \mathrm{raз}}}{c_{\mathrm{p} \text { Зот }}} .
$$

Для определения температуры продуктов сгорания (ПС) рассматривалось уравнение энергетического баланса для КС в целом:

$$
Q_{\text {ок }}+Q_{\text {гор }}+Q_{\mathrm{XP}}=Q_{\text {ПС }} \text {. }
$$

Тепловая мощность, вносимая в КС окислителем,

$$
Q_{\text {ок }}=\dot{m}_{\text {ок }} c_{\text {рок }} T_{\text {ок }},
$$

где $\dot{m}_{\text {ок }}, c_{\text {рок }}, T_{\text {ок }}$ - массовый секундный расход, удельная изобарная теплоемкость и температура окислителя на входе в КС.

Тепловая мощность, вносимая в КС горючим,

$$
Q_{\text {гор }}=\dot{m}_{\text {гор }} c_{\text {р гор }} T_{\text {гор }},
$$

где $\dot{m}_{\text {гор }}, c_{\text {ргор }}, T_{\text {rop }}-$ массовый секундный расход, удельная изобарная теплоемкость и температура горючего на входе в КС.

Тепловая мощность от химической реакции горения

$$
Q_{\mathrm{XP}}=\dot{m}_{\text {гор }} \mathrm{Hu}_{\mathrm{r}},
$$

где Нu - теплопроизводительность топливного газа; $\eta_{\text {г }}$ - полнота сгорания.

Тепловая мощность ПС на выходе из КС

$$
Q_{\text {ПС }}=\left(\dot{m}_{\text {ок }}+\dot{m}_{\text {гор }}\right) c_{\text {ргаз газ }} T_{\text {га }} .
$$

Тогда уравнение энергетического баланса для КС в целом примет вид

$$
\begin{gathered}
\dot{m}_{\text {ок }} c_{\text {р ок }} T_{\text {ок }}+\dot{m}_{\text {гор }} c_{\text {р гор }} T_{\text {гор }}+\dot{m}_{\text {гор }} \mathrm{Hu \eta}_{\text {г }}= \\
=\left(\dot{m}_{\text {ок }}+\dot{m}_{\text {гор }}\right) c_{\text {р газ газ }} T_{\text {газ }}
\end{gathered}
$$

или

$$
\begin{gathered}
\alpha K_{m 0} c_{\text {р ок }} T_{\text {ок }}+c_{\text {р гор }} T_{\text {гор }}+\mathrm{Hu \eta}_{\text {г }}= \\
=\left(\alpha K_{m 0}+1\right) c_{\text {р газ газ }},
\end{gathered}
$$

где $\alpha$ - коэффициент избытка воздуха; $K_{m 0}$ массовое стехиометрическое соотношение.

Следовательно, температура ПС в зоне пламени

$$
\begin{gathered}
T_{\text {газ }}=\frac{\alpha K_{m 0}}{\alpha K_{m 0}+1} \frac{c_{\text {р ок }}}{c_{\text {р газ }}} T_{\text {ок. вх }}^{\text {КС }}+\frac{1}{\alpha K_{m 0}+1} \frac{c_{\text {р гор }}}{c_{\text {р газ }}} T_{\text {гор. вх }}^{\text {КС }}+ \\
+\frac{1}{\left(\alpha K_{m 0}+1\right) c_{\text {р газ }}} \text { Hu }_{\text {г }} ;
\end{gathered}
$$

$$
T_{\text {газ }}=\varphi \frac{c_{\text {р гор }}}{c_{\text {ргаз }}} T_{\text {гор. вх }}^{\text {КС }}+(1-\varphi) \frac{c_{\text {р ок }}}{c_{\text {р газ }}} T_{\text {ок. вх }}^{\text {КС }}+\frac{\varphi \mathrm{Hu} \eta_{\text {г }}}{c_{\text {р газ }}},
$$

где смесевая доля горючего $\varphi=\frac{1}{\alpha K_{m 0}+1}$.

Температура ГВС может быть определена из уравнения теплового баланса для смеси

$$
Q_{\text {ок }}+Q_{\text {гор }}=Q_{\text {гвС }} \text {. }
$$

Тепловая мощность горюче-воздушной смеси в ЗОТ

$$
Q_{\text {ГВС }}=\left(\dot{m}_{\text {ок }}+\dot{m}_{\text {гор }}\right) c_{\text {р ГВС }} T_{\text {ГВС }} .
$$

Тогда уравнение энергетического баланса для ГВС принимает вид

$$
\dot{m}_{\text {ок }} c_{\text {р ок }} T_{\text {ок }}+\dot{m}_{\text {гор }} c_{\text {р гор }} T_{\text {гор }}=\left(\dot{m}_{\text {ок }}+\dot{m}_{\text {гор }}\right) c_{\text {р ГВС }} T_{\text {ГВС }}
$$

или

$$
\alpha K_{m 0} c_{\text {р ок } T_{\text {ок }}}+c_{\text {р гор }} T_{\text {гор }}=\left(\alpha K_{m 0}+1\right) T_{\text {ГВС }} \text {. }
$$

Следовательно, температура ГВС на входе в зону обратных токов

$$
T_{\text {ГВС }}=\varphi \frac{c_{\text {р гор }}}{c_{\text {р ГВС }}} T_{\text {гор. вх }}^{\text {КС }}+(1-\varphi) \frac{c_{\text {р ок }}}{c_{\text {р ГВС }}} T_{\text {ок. вх }}^{\text {КС }} .
$$

Удельная теплоемкость ГВС при заданном $\varphi$

$$
c_{\mathrm{p} \mathrm{ГBС}}=\varphi c_{\text {p гор }}+(1-\varphi) c_{\text {р ок }} .
$$

Удельная теплоемкость в ЗОТ при заданном коэффициенте эжекции 


$$
c_{\text {р зОт }}=K c_{\text {ргаз }}+(1-K) c_{\text {р гвС }} \text {. }
$$

Важным параметром, влияющим на процессы в 3ОТ утилизационной КС, является коэффициент эжекции $K$. В работе рассмотрены два варианта определения коэффициента эжекции.

В первом варианте коэффициент эжекции определялся по рекомендациям работы [17]:

$$
K=0,632\left(0,2 \frac{L_{3 О \mathrm{~T}}}{D_{\text {к }}}\left(n_{\text {кр }}+1\right)+0,04 n_{\text {кр }}^{2}\right),
$$

где $D_{\text {к }}-$ диаметр КС; параметр крутки $n_{\text {кр }}=0,1 \ldots 1,2[18]$.

Длина зоны обратных токов определяется по эмпирической зависимости, предложенной Б.Г. Мингазовым [15]:

$$
L_{\text {ЗОт }}=\left(1,31 n_{\text {кр }}^{0,56}+0,8\right) D_{\text {к }} \text {. }
$$

Расчеты параметров в зоне обратных токов проводились по следующему алгоритму:

1. Температура в 3ОТ задавалась равной температуре воспламенения ГВС (природный газ + воздух) $T_{3 о т}=923 \mathrm{~K}$.

2. По уравнению (2) определялась температура ПС в зоне пламени $T_{\text {газ }}$.

3. По уравнению (3) определялась потребная температура ГВС на входе в 30ну обратных токов $T_{\text {Гвс. }}$

В табл. 1 и на рис. 1 представлены результаты расчетов температуры в зоне пламени $T_{\text {газ }}$ и потребная температура ГВС на вхо-

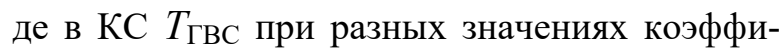
циента избытка воздуха при коэффициенте эжекции $K=0,14$.
Анализ данных на рис. 1 показывает, что для организации устойчивого горения обедненных смесей с коэффициентами избытка воздуха, превышающими нижний концентрационный предел горения, требуется предварительный внешний подогрев ГВС до температур $T_{\text {гвС }}=760 \ldots 860 \mathrm{~K}$.

Подогрев газовоздушной смеси до потребных значений возможен либо за счет дополнительного воздуха, либо за счет дополнительного подогрева топливного газа, либо за счет одновременного подогрева обоих компонентов [8].

В табл. 2 представлены варианты одновременного подогрева компонентов при разных значениях коэффициента избытка воздуха.

Таблица 1

Результаты расчетов при $K=0,14$

\begin{tabular}{|c|c|c|c|}
\hline$\alpha$ & $T_{\text {3ОТ }}, \mathrm{K}$ & $T_{\text {газ }}, \mathrm{K}$ & $T_{\text {ГВС }}, \mathrm{K}$ \\
\hline 2 & 923 & 1885 & 766,7 \\
\hline 3 & 923 & 1571 & 817,9 \\
\hline 4 & 923 & 1412 & 844,2 \\
\hline 5 & 923 & 1315 & 860,3 \\
\hline
\end{tabular}

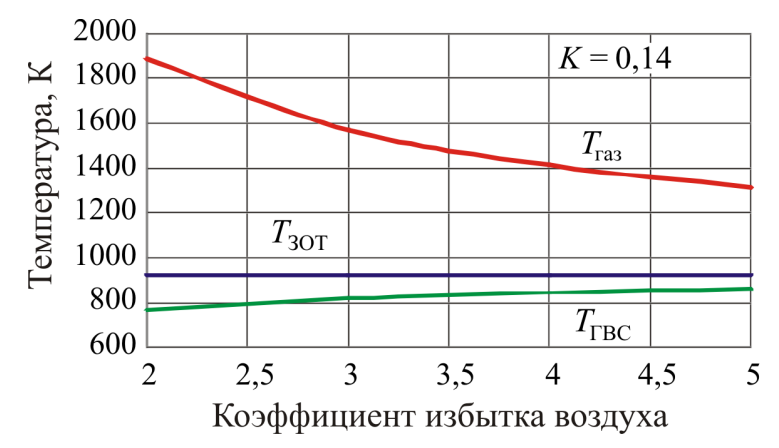

Рис. 1. Графические зависимости значений температуры от коэффициента избытка воздуха при $K=0,14$

\begin{tabular}{|c|c|c|c|c|c|c|c|c|}
\hline Температура & \multicolumn{2}{|c|}{$\alpha=2$} & \multicolumn{2}{|c|}{$\alpha=3$} & \multicolumn{2}{|c|}{$\alpha=4$} & \multicolumn{2}{|c|}{$\alpha=5$} \\
\hline$T_{\text {газ }}, \mathrm{K}$ & \multicolumn{2}{|c|}{1885} & \multicolumn{2}{|c|}{1571} & \multicolumn{2}{|c|}{1412} & \multicolumn{2}{|c|}{1315} \\
\hline$T_{\Gamma \mathrm{BC}}, \mathrm{K}$ & \multicolumn{2}{|c|}{766,7} & \multicolumn{2}{|c|}{817,9} & \multicolumn{2}{|c|}{844,2} & \multicolumn{2}{|c|}{860,3} \\
\hline \multirow{6}{*}{$\begin{array}{c}T_{\text {зот }}=923 \mathrm{~K}, \\
K=0,14\end{array}$} & $T_{\text {ок. вх }}^{\mathrm{KC}}, \mathrm{K}$ & $T_{\text {гор.в }}^{\mathrm{KC}}, \mathrm{K}$ & $T_{\text {ок. вх }}^{\mathrm{KC}}, \mathrm{K}$ & $T_{\text {гор.в }}^{\text {КС }}, \mathrm{K}$ & $T_{\text {ок. вх }}^{\mathrm{KC}}, \mathrm{K}$ & $T_{\text {гор. вх }}^{\text {KС }}, \mathrm{K}$ & $T_{\text {ок. вх }}^{\text {КС }}, \mathrm{K}$ & $T_{\text {гор. вх }}^{\text {КС }}, \mathrm{K}$ \\
\hline & 792,7 & 400 & 837,6 & 400 & 859,9 & 400 & 873,3 & 400 \\
\hline & 785,6 & 500 & 832,9 & 500 & 856,4 & 500 & 870,5 & 500 \\
\hline & 778,6 & 600 & 828,2 & 600 & 852,9 & 600 & 867,7 & 600 \\
\hline & 771,5 & 700 & 823,4 & 700 & 849,3 & 700 & 864,8 & 700 \\
\hline & 764,4 & 800 & 818,7 & 800 & 845,8 & 800 & 862,0 & 800 \\
\hline
\end{tabular}

Таблица 2

Одновременный подогрев компонентов при разных значениях $\alpha$ при $K=0,14$ 
Во втором варианте расчетов коэффициент эжекции $K$ определялся из условия, что при стехиометрическом соотношении компонентов $\alpha=1$ и стандартных значениях температуры окислителя и горючего на входе в КС температура воспламенения ГВС достигается только за счет обратных токов из зоны развитого горения без предварительного дополнительного подогрева воздуха и топливного газа.

Уравнение энергетического баланса для ЗОТ может быть представлено в следующем виде:

$$
h_{\text {ГВС }}+K h_{\text {газ }}=(K+1) h_{\text {зот }} \text {, }
$$

где $h_{\text {гвС }}, h_{\text {газ }}, h_{\text {зот }}$ - энтальпии горюче-воздушной смеси, продуктов сгорания и зоны обратных токов соответственно.

Следовательно, коэффициент эжекции

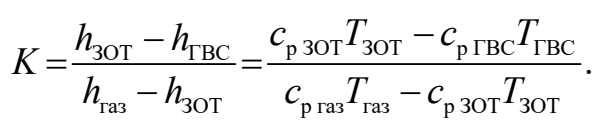

Предварительные оценочные расчеты показали, что можно принять следующие соотношения между теплоемкостями:

$$
\begin{gathered}
c_{\text {р зот }} \approx c_{\text {р ок }} ; c_{\mathrm{p} \mathrm{ГВС}} \approx c_{\text {р ок }} ; \\
c_{\text {р газ }} \approx 1,25 c_{\text {р ок }} ; c_{\text {p гор }} \approx 2,5 c_{\text {р ок. }} .
\end{gathered}
$$

Для приближенных расчетов можно использовать следующее выражение для вычисления коэффициента эжекции:

$$
K=\frac{T_{30 \mathrm{~T}}-T_{\text {ГВС }}}{1,25 T_{\text {газ }}-T_{\text {зот }}} .
$$

В табл. 3 и на рис. 2 представлены результаты расчетов температуры в зоне пламени $T_{\text {газ }}$ и потребная температура ГВС на входе в КС $T_{\Gamma \mathrm{CB}}$ при разных значениях коэффициента избытка воздуха и коэффициенте эжекции $K=0,30$.

Анализ данных на рис. 2 показывает, что для организации устойчивого горения обедненных смесей с коэффициентами избытка воздуха, превышающими нижний концентрационный предел горения, требуется предварительный внешний подогрев ГВС до значений температуры $T_{\text {гвС }}=640 \ldots 810 \mathrm{~K}$. Расчетные данные, полученные при $K=0,14$ и $K=0,30$, отличаются в среднем на $10 \%$.

В табл. 4 представлены варианты одновременного подогрева компонентов при разных значениях коэффициента избытка воздуха.

Таблица 3

Результаты расчетов при $K=0,30$

\begin{tabular}{|c|c|c|c|}
\hline$\alpha$ & $T_{30 \mathrm{~T}}, \mathrm{~K}$ & $T_{\text {га3 }}, \mathrm{K}$ & $T_{\text {ГВС }}, \mathrm{K}$ \\
\hline 2 & 923 & 1652 & 637,6 \\
\hline 3 & 923 & 1359 & 733,9 \\
\hline 4 & 923 & 1210 & 783,5 \\
\hline 5 & 923 & 1120 & 813,7 \\
\hline
\end{tabular}

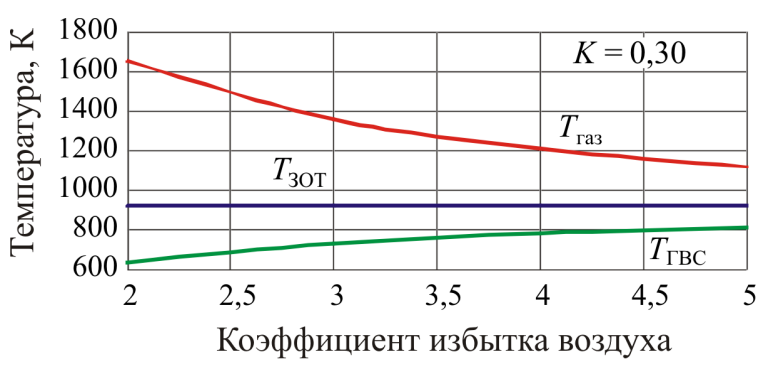

Рис. 2. Графические зависимости значений

\begin{tabular}{|c|c|c|c|c|c|c|c|c|}
\hline Температура & \multicolumn{2}{|c|}{$\alpha=2$} & \multicolumn{2}{|c|}{$\alpha=3$} & \multicolumn{2}{|c|}{$\alpha=4$} & \multicolumn{2}{|c|}{$\alpha=5$} \\
\hline$T_{\text {газ }}, \mathrm{K}$ & \multicolumn{2}{|c|}{1652} & \multicolumn{2}{|c|}{1359} & \multicolumn{2}{|c|}{1210} & \multicolumn{2}{|c|}{1120} \\
\hline$\overline{T_{\Gamma \mathrm{CBC}}, \mathrm{K}}$ & \multicolumn{2}{|c|}{637,6} & \multicolumn{2}{|c|}{733,9} & \multicolumn{2}{|c|}{783,5} & \multicolumn{2}{|c|}{813,7} \\
\hline \multirow{6}{*}{$\begin{aligned} T_{\text {зот }} & =923 \mathrm{~K}, \\
K & =0,30\end{aligned}$} & $T_{\text {ок } \mathrm{Bx}}^{\mathrm{KC}}, \mathrm{K}$ & $T_{\text {rop. } \mathrm{Bx}}^{\mathrm{KC}}, \mathrm{K}$ & $T_{\text {ок. вx }}^{\mathrm{KC}}, \mathrm{K}$ & $T_{\text {rop. } \mathrm{Bx}}^{\mathrm{KC}}, \mathrm{K}$ & $T_{\text {ок } \mathrm{BX}}^{\mathrm{KC}}, \mathrm{K}$ & $T_{\text {rop. } \mathrm{Bx}}^{\mathrm{KC}}, \mathrm{K}$ & $T_{\text {ок } \mathrm{Bx}}^{\mathrm{KC}}, \mathrm{K}$ & $T_{\text {rop. Bx }}^{\mathrm{KC}}, \mathrm{K}$ \\
\hline & 654,5 & 400 & 749,7 & 400 & 797,1 & 400 & 825,4 & 400 \\
\hline & 647,4 & 500 & 745,0 & 500 & 793,5 & 500 & 822,6 & 500 \\
\hline & 640,3 & 600 & 740,3 & 600 & 790,0 & 600 & 819,7 & 600 \\
\hline & 633,2 & 700 & 735,5 & 700 & 786,4 & 700 & 816,9 & 700 \\
\hline & 626,1 & 800 & 730,4 & 800 & 782,9 & 800 & 814,1 & 800 \\
\hline
\end{tabular}
температуры от коэффициента избытка воздуха при $K=0,30$

Таблица 4

Одновременный подогрев компонентов при разных значениях $\alpha$ при $K=0,30$ 
Таким образом, в результате проведенных исследований по влиянию подогрева свежей газовоздушной смеси на характеристики горения можно сформулировать следующие выводы:

1. Стабильное положение фронта пламени при коэффициентах избытка воздуха в интервале между верхним и нижним концентрационными пределами может быть обеспечено обратными токами из зоны развитого горения.
2. Для стабилизации фронта пламени при организации низкотемпературного горения при коэффициентах избытка воздуха $\alpha>2$ требуется дополнительный внешний подогрев компонентов перед подачей в КС в специальных теплообменниках отработанными на турбине газами.

3. Показано, что с увеличением коэффициента избытка воздуха в КС ГТУ усиливается роль внешнего подогрева ГВС при его нагреве до температуры воспламенения.

\section{Библиографический список}

1. Wierzba I., Kilchyk V. Flammability limits of hydrogen-carbon monoxide mixtures at moderately elevated temperatures // International Journal of Hydrogen Energy. - 2001. - Vol. 26, iss. 6. - P. 639-643.

2. Gibbon H.J., Wainwright J., LInRogers R. Experimental determination of flammability limits of solvents at elevated temperatures and pressures // Institution of Chemical Engineers Symposium Series. - 1994. - Vol. 134. - P. 1-12.

3. Effect of low temperature on the flammability limits of methane/nitrogen mixtures / Z. Li, M. Gong, E. Sun, J. Wu, Y. Zhou // Energy. - 2011. - Vol. 36 (9). - P. 5521-5524.

4. Dependence of the lower flammability limit on the initial temperature / T.A. Bolshova, V.A. Bunev, D.A. Knyazkov, O.P. Korobeinichev, A.A. Chernov, A.G. Shmakov, S.A. Yakimov // Combustion, Explosion, and Shock Waves. - 2012. - Vol. 48, iss. 2. - P. 125-129.

5. Catoire L., Naudet V. Estimation of temperature dependent lower flammability limit of pure organic compounds in air at atmospheric pressure // Process Safety Progress. - 2005. - Vol. 24 (2). P. $130-137$.

6. Обеспечение малоэмиссионной работы камеры сгорания в широком диапазоне климатических условий применительно к авиапроизводным ГТУ / Л.А. Булысова, А.Г. Тумановский, М.Н. Гутник, В.Д. Васильев, А.М. Сипатов, А.Д. Нугуманов // Электрические станции. - 2019. № 12 (1061). - С. 20-22.

7. Экспериментальные исследования модельной двузонной малоэмиссионной камеры сгорания ГТУ средней мощности / Л.А. Булысова, В.Д. Васильев, М.Н. Гутник, К.С. Пугач, М.М. Гутник, А.Л. Берне // Электрические станции. - 2019. - № 9 (1058). - С. 2 -7.

8. Организация низкотемпературного бедного горения утилизируемого газа / Н.Л. Бачев, А.А. Шилова, О.О. Матюнин, Р.В. Бульбович // Проблемы региональной энергетики. - 2020. № 3 (47). - C. 56-68.

9. Шилова А.А., Бачева Н.Ю. Определение коэффициентов избытка воздуха на верхнем и нижнем пределах горения забалластированных нефтяных газов // Вестник Пермского национального исследовательского политехнического университета. Аэрокосмическая техника. 2018. - № 53. - C. 77-85.

10. Шилова А.А., Бачев Н.Л., Бульбович Р.В. Влияние состава и параметров подачи нефтяного газа на его пределы горения // Аэрокосмическая техника, высокие технологии и инновации - 2019: материалы XX Всерос. науч.-техн. конф., г. Пермь, 14-16 ноября 2019 г.: в 2 ч. Пермь, 2019. - Т. 2. - С. 216-219.

11. Расширение пределов горения в пористой горелке с помощью внешнего подогрева / Ал.Ал. Берлин, А.С. Штейнберг, С.М. Фролов, А.А. Беляев, В.С. Посвянский, В.Я. Басевич // Доклады Академии наук. - 2006. - Т. 406, № 6. - С. 1-6.

12. Экспериментальное исследование расширения бедного предела горения метана с помощью внешних воздействий на физико-химические процессы в зоне прогрева пламени / П.А. Гусев, С.М. Фролов, О.Г. Скрипник, А.С. Штейнберг, А.А. Берлин // Горение и взрыв. 2009. - Вып. 2. - С. 7-11. 
13. Фролов С.М. Наука о горении и проблемы современной энергетики // Российский химический журнал. - 2008. - Т. 52, № 6. - С. 129-133.

14. Новый тип малоэмиссионных камер сгорания для газотурбинных установок на основе объемных проницаемых матриц / А.Н. Рахметов, В.М Шмелев, А.А. Захаров, В.С. Арутюнов // Горение и взрыв. - 2013. - № 6. - С. 61-64.

15. Мингазов Б.Г. Внутрикамерные процессы и автоматизированная доводка камер сгорания ГТД. - Казань, 2000. - 168 с.

16. Талантов А.В. Основы теории горения. - Казань: Изд-во Казан. гос. техн. ун-та, 1975. $-253 \mathrm{c}$.

17. Бакланов А.В. Исследование процессов в камере сгорания конвертированного авиационного ГТД с целью улучшения его экологических характеристик. автореф. дис. ... канд. техн. наук: 05.07.05 / Казан. гос. техн. ун-т им. А.Н. Туполева. - Казань, 2011. - 19 с.

18. Определение размеров зоны обратных токов трехмерной модели камеры сгорания ГТД с помощью пакета ANSYS FLUENT / В.В. Бирюк, М.Ю. Орлов, И.А. Зубрилин, Ю.А. Синеговский, А.В. Кривцов // Вестник Самарского государственного аэрокосмического университета. - 2011. - № 5 (29). - С. 44-47.

\section{References}

1. Wierzba I., Kilchyk V. Flammability limits of hydrogen-carbon monoxide mixtures at moderately elevated temperatures. International Journal of Hydrogen Energy, 2001, vol. 26, Issue 6, pp. 639-643.

2. Gibbon H.J., Wainwright J., Rogers R.L. Experimental determination of flammability limits of solvents at elevated temperatures and pressures. In Institution of Chemical Engineers Symposium Series, 1994, vol. 134, pp. 1-12.

3. Li Z., Gong M., Sun E., Wu J., Zhou Y. Effect of low temperature on the flammability limits of methane/nitrogen mixtures. Energy, 2011, vol. 36 (9), Yuan, pp. 5521-5524

4. Bolshova T.A., Bunev V.A., Knyazkov D.A., Korobeinichev O.P., Chernov A.A., Shmakov A.G., Yakimov S.A. Dependence of the lower flammability limit on the initial temperature. Combustion, Explosion, and Shock Waves, 2012, vol. 48, Issue 2, pp. 125-129.

5. Catoire L., Naudet V. Estimation of temperature dependent lower flammability limit of pure organic compounds in air at atmospheric pressure. Process Safety Progress, 2005, vol. 24 (2), pp. 130-137.

6. Bulysova L.A., Tumanovskiy A.G., Gutnik M.N., Vasilyev V.D., Sipatov A.M., Nugumanov A.D. Obespecheniye maloemissionnoy raboty kamery sgoraniya $\mathrm{v}$ shirokom diapazone klimaticheskikh usloviy primenitel'no $\mathrm{k}$ aviaproizvodnym GTU [Low emission operation of aero-derivative gt combustor under various ambient conditions]. Elektricheskiye stantsii, 2019, No. 12 (1061), pp. 20-22.

7. Bulysova. L.A, Vasilyev V.D., Gutnik M.N., Pugach K.S., Gutnik M.M., Berne A.L. Eksperimentalnyye issledovaniya model'noy dvuzonnoy maloemissionnoy kamery sgoraniya GTU sredney moshchnosti [Experimental investigation of a two-zone low emission combustor for a midpower gas turbine]. Elektricheskiye stantsii, 2019, No. 9 (1058), pp. 2-7.

8. Bachev N.L., Shilova A.A., Matyunin O.O., Bulbovich R.V. Organizatsiya nizkotemperaturnogo bednogo goreniya utiliziruyemogo gaza [Computational and Experimental Studies into Concentration Limits of Associated Petroleum Gas Combustion]. Problemele energeticii regionale, 2020, № 3 (47), pp. 56-68.

9. Shilova A.A.,. Bacheva N.Yu. Opredeleniye koeffitsiyentov izbytka vozdukha na verkhnem i nizhnem predelakh goreniya zaballastirovannykh neftyanykh gazov [Determination of the excess air coefficients at the upper and lower combustion limits of ballasted oil gases]. PNRPU Aerospace Engineering Bulletin, 2018, no. 53, pp. 77-85.

10. Shilova A.A., Bachev N.L., Bulbovich R.V. Vliyaniye sostava i parametrov podachi neftyanogo gaza na yego predely goreniya [Influence of composition and parameters of oil gas supply on its combustion limits]. Aerokosmicheskaya tekhnika, vysokiye tekhnologii i innovatsii 2019: materials of the XX All-Russian Scientific and Technical Conference, 2019, vol. 2, pp. 216-219.

11. Berlin Al. Al., Shteynberg A.S., Frolov S.M., Belyayev A.A., Posvyanskiy V.S., Basevich V.Ya. Rasshireniye predelov goreniya $\mathrm{v}$ poristoy gorelke $\mathrm{s}$ pomoshch'yu vneshnego podogreva 
[Expansion of the limits of combustion in a porous burner with the help of external heating]. Doklady Akademii nauk, 2006, vol. 406, No. 6, pp. 1-6.

12. Gusev P.A., Frolov S.M., Skripnik O.G., Shteynberg A.S., Berlin A.A. Eksperimentalnoye issledovaniye rasshireniya bednogo predela goreniya metana s pomoshchyu vneshnikh vozdeystviy na fiziko-khimicheskiye protsessy $\mathrm{v}$ zone progreva plameni [Experimental study of the expansion of the lean limit of combustion of methane with the help of external influences on the physicochemical processes in the heating zone of the flame]. Goreniye $i$ vzryv, 2009, No. 2, pp. 7-11.

13. Frolov S.M. Nauka o gorenii i problemy sovremennoy energetiki [Combustion Science and Problems of Modern Energy]. Rossiyskiy khimicheskiy zhurnal, 2008, vol. 52, No. 6, pp. 129-133.

14. Rakhmetov A.N., Shmelev V.M., Zakharov A.A., Arutyunov V.S. Novyy tip maloemissionnykh kamer sgoraniya dlya gazoturbinnykh ustanovok na osnove obyemnykh pronitsayemykh matrits [A new type of low-emission combustion chambers for gas turbine plants based on volumetric permeable matrices]. Goreniye i vzryv, 2013, No. 6, pp. 61-64.

15. Mingazov B.G. Vnutrikamernyye protsessy i avtomatizirovannaya dovodka kamer sgoraniya GTD [Intra-chamber processes and automated fine-tuning of gas turbine engine combustion chambers]. Kazan, 2000, 168 p.

16. Talantov A.V. Osnovy teorii goreniya [Foundations of the theory of combustion]. Kazan: Publishing house of Kazan State Technical University, 1975, 253 p.

17. Baklanov A.V. Issledovaniye protsessov v kamere sgoraniya konvertirovannogo aviatsionnogo GTD s tselyu uluchsheniya yego ekologicheskikh kharakteristik [Investigation of processes in the combustion chamber of a converted aircraft GTE with the aim of improving its environmental performance]. Ph.D. thesis. Kazan, 2011, 19 p.

18. V.V. Biryuk, M.Yu. Orlov, I.A. Zubrilin, Yu.A. Sinegovskiy, A.V. Krivtsov. Opredeleniye razmerov zony obratnykh tokov trekhmernoy modeli kamery sgoraniya GTD s pomoshchyu paketa ANSYS FLUENT [Determination of the size of the reverse flow zone of a three-dimensional model of the combustion chamber of a gas turbine engine using the ANSYS FLUENT package]. VESTNIK of Samara University. Aerospace and Mechanical Engineering, 2011, No. 5 (29), pp. 44-47.

\section{Об авторах}

Шилова Алена Алексеевна (Пермь, Россия) - аспирант кафедры «Ракетно-космическая техника и энергетические системы» ФГБОУ ВО ПНИПУ (614990, г. Пермь, Комсомольский пр., д. 29; e-mail: alyona1203@gmail.com).

Бачев Николай Леонидович (Пермь, Россия) - кандидат технических наук, доцент кафедры «Ракетно-космическая техника и энергетические системы» ФГБОУ ВО ПНИПУ (614990, г. Пермь, Комсомольский пр., д. 29; e-mail: bn154@yandex.ru).

Бульбович Роман Васильевич (Пермь, Россия) - доктор технических наук, профессор кафедры «Ракетно-космическая техника и энергетические системы» ФГБОУ ВО ПНИПУ (614990, г. Пермь, Комсомольский пр., д. 29; e-mail: bulbovich@pstu.ru).

\section{About the authors}

Alyona A. Shilova (Perm, Russian Federation) - PhD Student of Rocket and Space Engineering and Power Generating Systems Department, Perm National Research Polytechnic University (29, Komsomolsky av., Perm, 614990, Russian Federation; e-mail: alyona1203@gmail.com).

Nikolay L. Bachev (Perm, Russian Federation) - CSc in Technical Sciences, Professor of Rocket and Space Engineering and Power Generating Systems Department, Perm National Research Polytechnic University (29, Komsomolsky av., Perm, 614990, Russian Federation; e-mail: bn154@yandex.ru).

Roman V. Bulbovich (Perm, Russian Federation) - Doctor of Technical Sciences, Professor of Rocket and Space Engineering and Power Generating Systems Department, Perm National Research Polytechnic University (29, Komsomolsky av., Perm, 614990, Russian Federation; e-mail: bulbovich@pstu.ru).

Получено 16.02.2021 